Article

\title{
A Digital Coach Promoting Healthy Aging among Older Adults in Transition to Retirement: Results from a Qualitative Study in Italy
}

\author{
Sara Santini ${ }^{1, *}$, Flavia Galassi ${ }^{1}$, Johannes Kropf ${ }^{2}{ }^{-1}$ and Vera Stara ${ }^{3}(\mathbb{C}$ \\ 1 IRCCS INRCA-National Institute of Health and Science on Ageing, Centre for Socio-Economic Research on \\ Ageing, Via S. Margherita 5, 60124 Ancona, Italy; f.galassi@inrca.it \\ 2 AIT Austrian Institute of Technology $\mathrm{GmbH}$, Center for Health \& Bioresources, \\ 2700 Wiener Neustadt, Austria; Johannes.Kropf@ait.ac.at \\ 3 IRCCS INRCA - National Institute of Health and Science on Ageing, Scientific Direction, Innovative Models \\ for Ageing Care and Technology, Via S. Margherita 5, 60124 Ancona, Italy; v.stara@inrca.it \\ * Correspondence: s.santini2@inrca.it
}

Received: 31 July 2020; Accepted: 7 September 2020; Published: 9 September 2020

check for updates

\begin{abstract}
Global aging and increasing multimorbidity are questioning the sustainability of healthcare systems. Healthy aging is at the top of the world political agenda, as a possible means for hindering the collapse of care systems. In the aging process, the transition to retirement can lead to an improvement or a deterioration of physical and psychological health. Digital health coaching technology can support older adults at this stage, but what must be the role of such a solution in promoting healthy aging and shaping sustainable care? This qualitative study, carried out in Italy in 2019, involved 15 older workers, retirees, and colleagues. Based on a user-centered design approach, this study aims at gathering older adults' feelings on a digital health coaching technology for exploring this solution's potential in promoting healthy aging. Findings highlighted that the digital health coach may help older adults improve several health determinants, e.g., physical activity, cognitive capabilities, and social life, but it can also entail the risk of stigma and break people's privacy. The latter can be guaranteed by technology customization and codesign. Further research on the digital health coach benefits to boost healthy aging is needed to understand its potential for shaping future sustainable healthcare.
\end{abstract}

Keywords: aging population; assistive technology; digital health coach; healthy aging; long-term care; user-centered design; virtual coach

\section{Introduction}

Population is aging worldwide. There were 101.1 million older people-defined here as those aged 65 years and over-living in the European Union EU-28 at the start of 2018; this equated to almost one fifth $(19.7 \%)$ of the total population. During the next three decades, the number of older people in the EU is projected to follow an upward path, peaking at 149.2 million inhabitants in 2050. Their relative share in the total population will also gradually increase and is expected to reach $28.5 \%$ in 2050 [1]. Nevertheless, despite people living longer, the healthy life-year expectancy, i.e., the number of years free from disability, was estimated at 64.2 years for women and 63.7 years for men in the EU-27 in 2018 [2]. This means that about 9 years of later life can be characterized by one or more age-related chronic diseases (multimorbidity), this resulting not only in a lower quality of life, but also in a dramatic increase of the healthcare expenditure [3]. Thus, the increasing number of people with long-term care need is questioning the formal and informal healthcare systems sustainability due to the mismatch between care demand and availability of healthcare professionals and of public economic resources [4]. 
In order to mitigate the effects of the aging population on the whole society, and in particular on the healthcare systems, 194 countries in the world, the European Union included, adopted the global strategy and action plan on aging and health (2016-2030), which is aimed at the full promotion of healthy aging, defined "as the process of developing and maintaining the functional ability (i.e., people's capabilities of being and doing what they have reason to value) that enables well-being in older age" [5]. The healthy aging concept embeds and partly advances the active aging paradigm [6-8], meant as a process of optimizing opportunities for health and participation in the social, civic, cultural, and spiritual life realms for bettering the quality of later life [9].

The global strategy and action plan on aging and health is also aligned with the 2030 Agenda for Sustainable Development Goals [10], which aims to ensure that every human being can fulfill their potential in dignity and equality in a healthy environment. Hence, promoting healthy aging means adopting measures for preventing and delaying the onset of noncommunicable diseases and minimizing loss in autonomy by ensuring supportive environments, and effective healthcare systems for managing chronic conditions. Moreover, according to the WHO's definition of health as a state of complete physical, mental, and social well-being [11], the healthy aging concept goes beyond the concept of health as an absence of organic disease for, conversely, enhancing health in all its dimensions, i.e., social and psychological dimensions, and throughout the individuals' life-course $[7,8]$. In fact, circumstances throughout childhood and adult age influence health in old age, so people in all ages should adopt healthy behaviors such as balanced diet, constant physical activity, social contacts, and meaningful relationships, in order to pave the way towards a healthy and active aging, whose undermining factors are, conversely, isolation, invisibility, and loneliness [12].

Within the older adult population, individuals aged between 55 and 70, including the so called older workers [13] and new retirees, are worth special attention because the transition from work to retirement can expose them to the risk of poor health conditions and a lack of independence in absence of the adoption of a healthy lifestyle oriented toward physical activity, psychological well-being, and social participation [14].

In fact, the literature is rather firm in stating that the transition from work to retirement is a life event that entails a complex psychological challenge, including leaving one's professional life and organizing/enjoying the newly available free time [15]. This transition may put individuals at risk of poverty, emotional discomfort, and isolation [16], which can undermine people's health [11]. Nevertheless, there is not a general consensus in the literature on the impact of the retirement specifically on older adults' health. Although some studies highlighted that retirement can improve the overall psychological and physical health of individuals [16-18], others argued that the protective effect of retirement on the health status can change over time [19]. Such an effect indeed, may be stronger for individuals who have been retired for less than two years, and still in the "honeymoon" stage [20], and being weaker among people retired for more than two years who may live a "disenchantment" phase [21]. According to the above, retirement is considered as a longitudinal process during which retirees' levels of adjustment may fluctuate as a function of individual resources and changes in these resources [22]. In the long-term, indeed, retirement can also mean the slowing down, if not the interruption, of cognitive stimuli, social relationships, and physical activity. This can compromise the image that older people have of themselves, diminish their sense of purpose, and lower the levels of self-esteem and self-efficacy, which may worsen both mental and physical health [23]. As the years pass, loneliness and depression tend to increase among retirees, while mental health and satisfaction with life tend to decrease [15].

Older people in the cusp of retirement may be concerned about their future and worried to jump into the unknown. They may be worried that retirement means inactivity and social exclusion and that they would become a burden for youngster family members (e.g., children) and for society. In particular, the fear of getting ill and declining health is fairly common [24].

The extent to which retirees can take the retirement as a new opportunity for social participation and inclusion depends on endogenous factors, e.g., personal choice and exogenous factors like labor 
markets, pension, and welfare systems [25]. Retirement also reflects societal values and cultural norms that influence older employees and retirees' plans for retirement [26]. For example, people who belong to family oriented societies may be more likely to spend time caring for older family members and grandchildren, while people with labor market oriented beliefs may be keener to re-enter the workforce [27]. In this concern, previous research demonstrates that pre-retirement planning can predict post-retirement well-being and satisfaction [28,29]. Nevertheless, in western developed countries, retirement satisfaction is most associated with good family relationships, social inclusion, and participation, e.g., volunteering and leisure activities, such as traveling, regardless of pre-retirement planning [30].

In light of the above, retirement can be considered as a personal and not standardized process [31] entailing many variables that can influence its course.

Therefore, carrying out health promotion interventions targeting older adults aged between 55 and 70 years, could be a strategy for early interception of their needs and keeping them healthy and active longer. Health promotion programs targeting this kind of end-user (i.e., people between 55 and 70 , living the transition to retirement, or just retired), seem to be effective when they are shaped specifically for older adults by different means, e.g., photos, graphics, and videos with testimonies of people over the age of 50 who describe their health practices, difficulties, goals, and successes; when the activities suggested by the programs cover the major health promotion topics of healthy aging (i.e., diet, physical activity, stress management, and tobacco use); when longitudinal outcome assessments are included, and the outcomes help technicians shape and update further offered activities [32]. Since retirement is a dynamic and very personal process [31], the programs targeting older people in transition to retirement should be flexible and customizable in order to adapt to the constant change in physical, psychological, social, and economic determinants of health of the end-users.

The role that new technologies can play in enhancing older adults' health and well-being is still an open question. In fact, despite the general interest around people in transition to retirement on one side, and the use of assistive technology for older people with disability on the other, there is still a paucity of studies exploring and experimenting the effectiveness of new technologies in promoting the healthy aging of people in this phase of life. Conversely, the current technology could be in a position to counteract social isolation and the emotional discomfort that may arise as a result of retirement, as well as to promote independent living and active and healthy aging of older adults by means of relatively simple assistive aids, as well as by high-tech solutions [32,33]. In comparison to the traditional offline health promotion programs, online digital health promotion programs can not only improve diet behavior, physical activity, and social inclusion, but they can also have the advantage of being free or low cost, and accessible at all times and anywhere, such that the pressure on health systems (e.g., due to the increasing demand of workforce and expenditure for care) would be relieved and the assistance of an increasing number of elderly people with chronic diseases would be more sustainable.

Despite the promising bond between the aging and innovation trends, there can be several barriers to the use of technology by older adults. First, the common use of modern technologies by older adults in everyday life is not spread globally due to social factors (age, education, and gender), cultural characteristics of individuals (digital literacy and trust in technology), psychological issues (self-efficacy, comfort), and technological and economic factors (inequality access to technology, price-value) [34]. Moreover, other barriers for using healthcare technologies have their roots in the technology design phase, and are the lack of acceptance, usability, and reliability of healthcare technologies by end-users. This approach is not recent by the fact that since 2005, according to McCreadie and Tinker [35], the interactions between a "felt need" for assistance, the recognition of "product quality", the efficiency, reliability, simplicity, and safety of the technology, and its availability and cost, are the basic components of a complex model of acceptability for assistive technology to older people. Similarly, Melenhorst et al. [36] in 2001 suggested that the lack of perceived advantages or benefits might explain older adults' reluctance to use digital technologies. An integrated approach to identifying enablers and barriers to older adults' adoption of technology is proposed by Lee and 
Coughlin [37], who classify common themes and concepts in the field of gerontology, information technology, behavioral sciences, human factors, consumer studies, and design. Factors such as usability, affordability, accessibility, emotion, confidence, independence, compatibility, reliability, social, technical support, and cost represent the complex and multiple aspects of a comprehensive understanding of older adults as users and consumers of technology, next to other factors commonly widely used under the umbrella of the technology acceptance model (TAM) [38,39] and its various TAM extensions. Moreover, technologies need to match the needs of users without causing social embarrassment and stigma. For example, the functionality of assistive devices (i.e., age-related health monitoring devices could be perceived as disabling or lacking control), their aesthetics can also influence the relationship between product and user since technologies have symbolic meanings in contemporary societies and the way people use them can confirm and reinforce certain values [40-42]. Therefore, the design of technologies should not interfere negatively with the process of acceptance. The latter aspects are still not easy to tackle despite being essential to ensure the effectiveness of the technology. The user centered design (UCD) [43] approach is one of the most recognized for overcoming these barriers, because it ensures a continuous and iterative involvement of end-users for capturing their needs, capabilities, and limitations, in order to identify technology requirements and thus to develop technology that can meet users' needs and expectations.

This study is part of the European project "Virtual coaching to support a healthy and meaningful life of older adults and employees in their retirement process" (AgeWell) (aal-2018-5-92-CP) that is aimed at developing a UCD personalized digital health coach (DHC) solution designed for supporting the healthy aging of older adults aged 55-70, especially of older workers and new retirees. The AgeWell DHC is an embodied conversational agent (ECA)—software specifically designed to work and act like a human. The advantage of this virtual humanoid character is almost similar to an in-person health coach offering self-management through personalized guidance and support available at any time and any location using a smartphone application. These characteristics make the DHC an inexpensive technology.

The study presented here is aimed at increasing the knowledge on the potential contribution of the DHC systems for promoting older adults' healthy aging, thereby delaying intensive care needs and improving individuals' independent life.

\section{Materials and Methods}

\subsection{Sample Inclusion Criteria and Recruitment Strategy}

This study is based on the outcomes of the codesign process based on the UCD approach carried out for the development of the AgeWell DHC. The study foresaw three waves of three focus groups each, carried out in Austria, Italy, and the Netherlands in Spring and Autumn 2019, and in Spring 2020. This paper reports the findings of the first wave of the three focus groups carried out in Italy and involving a nonprobability purposive convenience $[44,45]$ sample of 15 participants: five older workers, five retirees, and five colleagues. Older employees were included if they were 55 years old and over, in good health, and at least two years to retirement, such that they could have already developed feelings and thoughts on retirement since it was quite a close event. Retirees' inclusion criteria were 55 years old and over, in good health, and retired for three years, since literature emphasizes that more than two years are needed to adapt to the new condition $[46,47]$. The only inclusion criteria for colleagues of older workers and retirees was being in close relationship with the latter, i.e., having spent the majority of the work time together and knowing some personal and family details of their present or past colleagues.

Older workers and retirees matching the inclusion criteria were recruited within the employees of the National Institute of Health and Science on Aging (INRCA), a public body managing five geriatric hospitals and residential care facilities in Italy and carrying out clinical, biological, and socioeconomic research on aging. Therefore, within INRCA there were different professionals, 
covering different positions within the organization, i.e., white collars, nurses, general practitioners, occupational therapists, administrative professionals, biologists, and researchers in gerontology, geriatrics, and biology. The human resource office of INRCA provided researchers with a list of older employees and retirees matching the inclusion criteria. Researchers contacted potential participants, informed them on the project objectives, ways and times, and underlined that participation in the study was completely voluntary, and that they could leave the study at any time without providing any explanation. Thus, researchers asked them some screening questions for checking their inclusion. Older employees and retired older people who matched the inclusion criteria and accepted to take part in the study were asked to provide names and contacts of colleagues to include in the focus groups. Nobody refused to attend and the participants were provided with and asked to sign a written document providing their informed consent to data treatment in accordance with the GDPR 2018 and the national legislation on privacy and data protection. Approval by the ethics committee was not mandatory because this was an observational study.

\subsection{Data Collection Methodology}

The focus group appeared to be one of the more suitable and used methodologies for collecting users' needs, feelings, and impressions on a new and still unknown technology such as DHC [34,48]. In order to ensure the study's trustworthiness [49], different perspectives were represented by involving three types of participants: older workers, retirees, and respective colleagues. Moreover, three researchers analyzed data independently in order to minimize the research bias [50-54]. The discussions were conducted by a researcher playing the role of moderator while another researcher was observing the discussions, took notes, and timed the session. The topic guide developed within three areas: sentiments and needs according to retirement, feelings and needs on a digital coach, and participants' feedback after showing the digital health coach and the technology used to run it (Table 1).

Table 1. Topic guide issues and questions.

\begin{tabular}{|c|c|}
\hline Issues & Questions \\
\hline $\begin{array}{l}\text { Feelings and needs on retirement } \\
\text { (retirement representations) }\end{array}$ & $\begin{array}{c}\text { What are your feelings about retirement in general? } \\
\text { What are your/their hopes, needs, and fears concerning health, family and } \\
\text { the social system? }\end{array}$ \\
\hline $\begin{array}{l}\text { Feelings and needs regarding a digital } \\
\text { health coach }(\mathrm{DHC})\end{array}$ & $\begin{array}{c}\text { How could a digital health coach help you before and during retirement? } \\
\text { What are your wishes and expectations regarding a virtual coach? } \\
\text { Where do you see challenges? } \\
\text { If you could design your personal digital coach, how would you design it? } \\
\text { What are your preferences regarding the functions? } \\
\text { How do you want to access the coach and why? }\end{array}$ \\
\hline $\begin{array}{l}\text { Feedback before and after showing a DHC } \\
\text { via storyboards }\end{array}$ & $\begin{array}{l}\text { What is your first impression on DHC? What do you like/dislike and why? } \\
\text { What should be changed in order to recommend the coach to your family } \\
\text { and friends? } \\
\text { What do you like and dislike about the graphic solution in the system } \\
\text { (colors, lettering, images)? } \\
\text { How often could you imagine to use such a coach (once/twice a day, } \\
\text { for } 5 \text { min, shorter/longer)? } \\
\text { How could the coach help you to cope with professional or } \\
\text { private challenges? }\end{array}$ \\
\hline
\end{tabular}

First, researchers explained the aim of the focus group and focused the discussion on feelings, fears, and expectations about retirement, which considered the contextual and background factors that could influence the usability and acceptability of the digital health coach.

Then, the participants were asked about their digital literacy, usage, and opinion on technology. Finally, the moderator showed the storyboard of the DHC (Figure 1) and asked participants for their first reactions. 

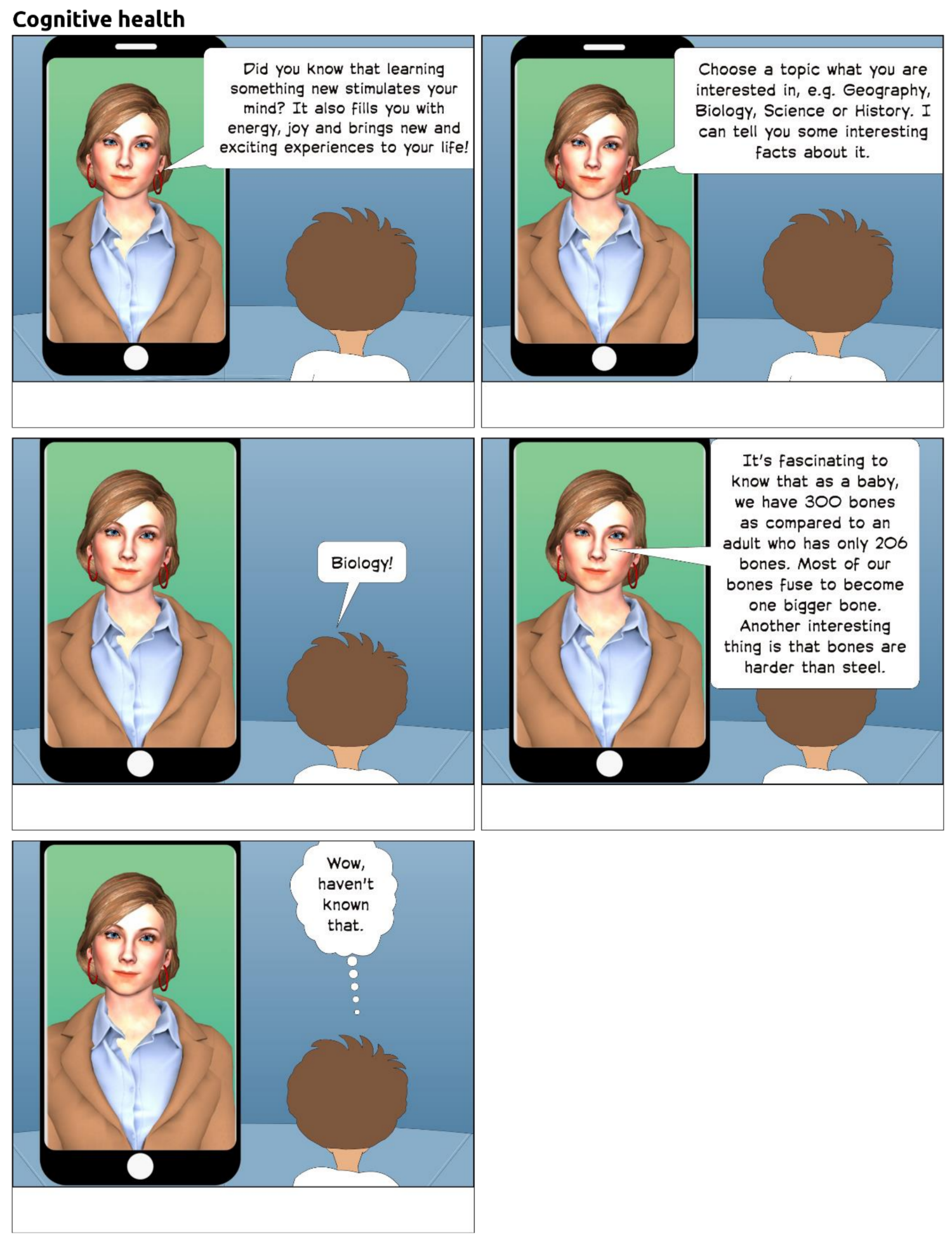

Figure 1. An example of cognitive input via a storyboard used during the focus group. The storyboard shows how the users would interact with the digital coaching.

\subsection{Data Analysis Methodology}

Focus-group discussions were digitally recorded, transcribed verbatim, and analyzed using the framework analysis method [54-56]. Researchers familiarized with the texts through the immersion in the raw data that were divided into chunks and associated with codes systematized into a tree chart. Codes were combined under main themes and the latter identified once the consistency within 
different codes under the same theme was assessed. Repeated patterns/themes through the data set were identified and a code associated with every chunk of text. In a second step, two or more codes were combined and different codes sorted into potential themes and subthemes. Then, data were shifted and these activities lead to sorting out quotes and making comparisons among them [57]. Data were rearranged according to the appropriate part of the thematic framework to which they related. The final step was the interpretation of data through the associations between themes. The analysis therefore, started deductively from aims and objectives of the study embedded in the topic guide, but also reflected the original observation of the respondents according to an inductive approach.

\section{Results}

As mentioned above, the first focus group included five older workers, the second five retirees, and the third group embedded five colleagues of retirees or of older workers. In the cluster of older workers there were two women and three men aged between 60 and 66 years. Retirees were three women and two men aged between 62 and 70. The age range of colleagues of retired people was larger (between 37 and 58 years), and the group was made of three women and two men. Participants had different professional profiles: there were sociologists, administrative assistants, and health professionals. Table 2 reports participants' characteristics and the user number associated with corresponding quotations reported in this section.

Table 2. Participants' gender, age, and professional profile.

\begin{tabular}{ccccc}
\hline Group & Participants n. & Gender & Age & Professional Profile \\
\hline \multirow{3}{*}{ Older employees } & P1 & Female & 60 & Sociologist \\
& P2 & Male & 66 & Biologist \\
& P3 & Male & 64 & Practitioner \\
& P4 & Female & 64 & Administrative Assistant \\
& P5 & Male & 66 & Administrative Assistant \\
& P6 & Female & 70 & Sociologist \\
Retirees & Female & 66 & Biologist \\
& P8 & Female & 62 & Administrative Assistant \\
& P9 & Male & 67 & Administrative Assistant \\
& P10 & Male & 67 & Physiotherapist \\
& P11 & Male & 52 & Sociologist \\
& P12 & Female & 37 & Psychologist \\
& P13 & Female & 55 & Engineer \\
P14 & Male & 58 & Administrative Assistant \\
& P15 & Female & 43 & Research assistant \\
\hline
\end{tabular}

As mentioned above, according to the framework analysis, the chunks of focus-group transcriptions were associated to codes and the latter were merged in themes. Table 3 shows the correspondence between themes and codes.

In the following subparagraphs, participants' feelings, needs, and expectations on retirement are reported, followed by individuals' digital literacy and their feelings regarding expectations and risks of DHC use. 
Table 3. Themes and codes arising from the thematic analysis per groups of respondents.

\begin{tabular}{|c|c|c|c|}
\hline \multirow[t]{2}{*}{ Themes } & \multicolumn{3}{|c|}{ Codes } \\
\hline & Older Workers & Retirees & Colleagues \\
\hline \multirow{5}{*}{$\begin{array}{l}\text { Expectations according to } \\
\text { retirement in general } \\
\text { Complaints } \\
\text { Fears related to retirement in general } \\
\text { Complaints }\end{array}$} & More free time & More free time & Not applicable \\
\hline & Freedom & Freedom & \\
\hline & Not applicable & The loss of social relationships & Not applicable \\
\hline & Deterioration of health status & Deterioration of health status & Not applicable \\
\hline & Not applicable & $\begin{array}{l}\text { Loss of social contacts and cognitive } \\
\text { stimuli }\end{array}$ & Not applicable \\
\hline $\begin{array}{l}\text { First reaction to the DHC before } \\
\text { showing the storyboards }\end{array}$ & Skeptical & Suspicious & Skeptical \\
\hline \multirow{3}{*}{$\begin{array}{l}\text { Feedback after showing DHC via } \\
\text { storyboards }\end{array}$} & Fun and Game & Positive attitude towards the DHC & Fun and Game \\
\hline & $\begin{array}{l}\text { Understanding of DHC potential for } \\
\text { healthy aging }\end{array}$ & $\begin{array}{l}\text { Understanding of DHC potential for } \\
\text { healthy aging }\end{array}$ & $\begin{array}{l}\text { Understanding of DHC potential at } \\
\text { company level }\end{array}$ \\
\hline & Provide information & Motivate to healthy lifestyle & $\begin{array}{l}\text { At company level for smoothing the } \\
\text { retirement of older employees }\end{array}$ \\
\hline \multirow{3}{*}{ Suggestions on functions of DHC } & $\begin{array}{l}\text { Motivate to practice physical } \\
\text { activity }\end{array}$ & $\begin{array}{l}\text { Plan physical activity, travels, and } \\
\text { social commitments }\end{array}$ & $\begin{array}{l}\text { Motivate to practice physical } \\
\text { activity }\end{array}$ \\
\hline & Stimulate cognitive activity & $\begin{array}{l}\text { Give advice on economic and legal } \\
\text { issues related to retirement }\end{array}$ & $\begin{array}{l}\text { Help socialization by connecting } \\
\text { people virtually }\end{array}$ \\
\hline & $\begin{array}{l}\text { Prepare older adults to retire by } \\
\text { boosting self-awareness }\end{array}$ & $\begin{array}{l}\text { Stimulate interests and brain } \\
\text { activities }\end{array}$ & $\begin{array}{l}\text { Prepare older adults to retire by } \\
\text { boosting self-awareness }\end{array}$ \\
\hline \multirow{3}{*}{$\begin{array}{l}\text { Risks to avoid in developing the } \\
\text { concept for the user interface }\end{array}$} & Stigmatization & Stigmatization & Stigmatization \\
\hline & Privacy & Privacy & Privacy \\
\hline & Substitution of cognitive capabilities & Substitution of cognitive capabilities & Acceptance \\
\hline
\end{tabular}

\subsection{Feelings, Needs, Expectations, and Plans for Retirement}

Older workers and retirees involved in the focus groups agreed on considering retirement as a breaking point and the beginning of a "new life".

In the group of retirees, two main themes arose from the analysis of the sentiments: happiness for freedom and concern for the loss of social contacts, and showing ambivalent feelings towards the retirement. On one side, they realized having more time to devote to their interests and that they could plan their days as they preferred-they had been experiencing time free from work, duties, and working condition, as highlighted by a retired woman: "My PC password is "newlife"! I started a new life when I retired. I went back to being young. I go to bed very late (even at 2.30 am) and get up later. Positive aspects of retirement are gym three times a week, walking, theater, a few conferences, phone calls to elderly aunts, seeing friends" (P8).

On the other side, they complained about the loss of social contacts and the dearth of motivation and inputs for increasing social life. The two sides of the same coin are plastically described by the following quotation: "The positive side of retirement is freedom. The negative side is the interruption of many human relationships that gave me many stimuli (P6).

Other retirees pointed out more the freedom they were experiencing as retirees, underlying the power of working environment in conditioning thinking and daily activities: "I found freedom after 40 years of work" (P7), and "I can experience greater freedom to act and think without conditioning" (P10).

They also reported the need for more information about cultural events, e.g., concerts, conferences, art exhibition, because they thought that these events can represent chances for improving social life and stimulating brain activities. Someone highlighted the need for receiving advice on the opportunities and rights of pensioners.

As far as physical activity was concerned, most of retirees practiced gym and outdoor activities, such as sailing and walking, often regularly two or three times a week. The most common concern within this group was the fear of getting ill and having long-term care needs: "The biggest fear is that it doesn't always go on like this: we age and aging brings disease. The hope is to maintain health as it is now and to allow my children a peaceful life; that is, that they do not have to assist me or help me financially to guarantee my care" (P10).

Older workers referred to being very busy for balancing work and family time. Older workers without family responsibilities, such as grandparenthood or caregiving for older parents, had time to spend in hobbies and interests. Moreover, they mentioned having an intensive social life and being in contact with many people they met at work and within their family and friendship network. 
Within this group, the plans for retirement mainly concerned traveling and learning and, just in the case of a doctor, continuing working: "I would like to structure new private medical activities, but without excesses because I want to dedicate myself also to my wife and my grandchildren" (P3). Among older workers, fears related to retirement were not missing and they mainly concerned physical and psychological health, e.g., body weight increase, disability onset, and laziness, as depicted by the following quotations: "I'm afraid to get sick and not self-sufficient because I am aging [ ... ] and to become lazy, because of the lack of inputs" (P2).

Colleagues and excolleagues of older workers and retirees gave some interesting insights. In particular, they stressed that colleagues most attached to work felt the feeling of emptiness after retirement more than others. They agreed in pointing out that the reaction to retirement of their colleagues or excolleagues had been very personal and it depended on personal relationships (e.g., the presence of care responsibilities for grandchildren and/or very old parents), and on the attachment to work. The group of colleagues identified two possible reactions to retirement, described below: "Retirement is a very subjective aspect, but if I think of the person I am here for, I don't think it will have great difficulties because she is always a very busy person with many things in mind, who knows how to work on herself, and I believe she will prepare in time and will be able to manage the sense of emptiness without suffering it" (P15) and "If I think of the person I represent, who has already retired, it is a woman extremely attached to work, which was the predominant aspect of her whole life and her main passion. I certainly know that you felt a strong emptiness when you stopped working" (P12).

\subsection{Digital Literacy and Usage of Technology}

The participants were asked about their level of digital literacy. Older workers as well as retirees used information and communication technology (ICT) daily and regularly: the first at work, e.g., e-mail and web platforms for sharing documents, the second for searching for public events, art exhibition, conferences, and for organizing their travels. Both groups surfed the internet in everyday life, searching for news and advice. Older workers as well as retirees were part of social networks, e.g., Whatsapp and Facebook, and they often communicated by means of them. All older workers used different types of apps on their smartphones, especially for monitoring physical activity, mostly walking. One retiree used a smartwatch.

In short, the use of technology was part of their life so we can say that they were digitally literate. Nevertheless, nobody was using a DHC, for neither physical activity nor other daily activities.

\subsection{Feelings and Expectations on DHC}

After explaining in words the DHC characteristics and possible functions, participants to the focus groups were asked to what extent a DHC could help them age healthy. Initially, retirees did not acknowledge the usefulness of a DHC for continuing living healthy because, in their opinion, the technology can be applicable mainly to older people with physical and cognitive impairment. Since they felt in good health condition, initially they did not find a DHC a useful device.

Older workers were very skeptical on the usefulness of the DHC for stimulating healthy lifestyle and, among the retirees the prevalent feelings were mistrust and suspect towards the DHC, which they look at like a manager giving orders: "In my opinion, retirement means also to respect one's time. If I have a technology that pounds me all day, I no longer see respect for the pensioner. I don't want to have schedules or programs anymore and I don't want technology to force me to do what I have to do. I see it as a lack of respect for my timing and freedom. Moreover, what I want to do changes from day to day, so it would be very difficult even to personalize the digital coach inputs" (P4). Conversely, retirees were experiencing the freedom of being masters of their time, so they wanted to feel free to decide what to do day-by-day without restrictions.

In the group of colleagues of older workers and retirees, the first reaction was of skepticism towards the DHC that they found quite useless.

Conversely, after introducing DHC possible uses and functions via storyboards (Figure 1), e.g., giving advice, motivating, monitoring physical activity, participants of the three groups were less 
skeptical and more confident in the usefulness of the DHC, and especially retirees were more open to the idea of using it.

Thus, the researchers started to explore with them the possible functions of this technical solution. The following paragraph reports participants' inputs on the DHC functions, addressing the main objective of the USD approach, i.e., finding the meeting point between end-users' needs and technology requirements.

\subsection{Digital Health Coach Functions in Participants' Opinion}

Retirees suggested that the DHC had the function of (a) planning physical activity, travels, and social commitments; (b) stimulating interests and brain activities; (c) providing information on cultural and social events; and (d) giving advice on economic and legal issues related to retirement. Especially the planning function was unanimously stressed by retirees because it was meant as a useful tool in order not to waste but to fully exploit the free time they had at their disposal.

The group of older workers and the group of colleagues/excolleagues agreed that motivating older adults to adopt healthy lifestyles should be the main function of the DHC. The second function could be to prepare older adults to retire by enhancing their self-awareness and helping them to identify their needs and desires. Finally, the group of colleagues/excolleagues emphasized the potential of the DHC in connecting older people virtually by building small communities.

All participants of the three groups agreed that a DHC should be an avatar running on the smartphone. The latter, being portable, was deemed respectful of the freedom of retirees who finally can move and travel without work time restrictions.

The DHC was unanimously acknowledged as a useful tool to facilitate the transition to retirement: "The digital coach should intervene before retirement to prepare people for what will happen. Indeed, many people do not have the opportunity to prepare for retirement." (P1).

An excolleague of a retiree suggested the use of the DHC by companies in order to accompany the person towards the retirement during the last years of work: "Companies should offer a guidance service to older workers to help them understand how they can happily experience the transition to retirement." (P11).

Colleagues and excolleagues agreed on the fact that "the digital coach should be attractive and fun: something like a game" (P12). Moreover, the identification of the specific needs of this target emerged as an essential prerequisite to design a technology that can meet the individuals' preferences, thus being fully acceptable, usable, and effective: "The digital coach should ask the subjects some questions to know health, socialization, and well-being needs. Therefore, based on the answers, the digital coach should propose a series of activities compatible with the subject preferences." (P11).

Within the group of older workers arose the necessity of a DHC meeting the numerous changes that people have to face during the transition from work to retirement. These changes concern financial aspects, social activities, health, and life style, as depicted by the following quotation: "There is an economic change, a change in health, in legislation, in educational initiatives, and in facilitations for pensioners. People often don't know a lot of things because they never got information before they retired. They have so many opportunities that they do not know because they do not care until they are retired, so it may be useful to inform them before the transition to retirement" (P1).

\subsection{Risks within the Usage of the Digital Health Coach}

Participants identified three main risks in the use of the DHC: stigmatization, privacy violation, and substitution of human beings' cognitive and decision capabilities. The following quotations depict each of these risks.

"Needing a virtual coach like this means being old and not self-sufficient ... it makes me feel even older." (P14).

"An avatar works well only if it is connected with personal data management tools. So there could be a privacy problem." (P13). 
"For healthy people, the digital coach is useless: it is foolish to let me do things that I can do. Delegating these activities to these technologies damages the maintenance of my autonomy." (P10).

The respondents identified two measures for overcoming these limitations: (a) a correct programming of the digital coach and (b) the involvement of a human being for facilitating the use of this technology: "It would be useful if there was an operator collaborating with the person who has to retire, sets up and customizes the product, and carries out a sort of accompanying function" (P11).

\section{Discussion}

This study was aimed at collecting end-users' attitude and expectation towards the use of a DHC for exploring the potential of this kind of technology in promoting older adults' healthy aging. To this purpose, three focus groups with older workers near to retire, retirees, and their colleagues/excolleagues were carried out in Italy.

In line with the literature $[15,16,22,23]$, findings showed that retirement was generally meant and experienced as an existential change and as a fundamental step towards a new life by both older workers and retirees participating to this study. Retirees had ambivalent feelings about their experience of retirement, swinging between sense of freedom and sense of emptiness, especially due to the loss of social relationships, this confirming what was underlined by previous studies on retirement [22,23]. They referred to being concerned for their health and they were especially worried to have long-term care need in a near future, and to lose their independence. They expressed the need to be informed about social, educational, and cultural events, and retirees' rights.

As well, older workers seemed to be quite concerned for their physical health and psychological well-being after retirement. They were fully aware and conscious of the risks of retirement; i.e., loss of cognitive stimuli and social contacts and depression, but also of the potentialities of this change i.e., the chance of having more time, the freedom, and the sense of being masters of their own life [58].

Older workers and retirees taking part into this study had a good level of health and digitally literacy. Indeed, they recognized the ubiquitous use of technology and innovative solutions in everyday life, e.g., by using different typologies of apps, thus confirming that the stereotype of older adults as sick, unable to learn, slow, disinterested in new activities, and technophobic has been left behind by the last generation of new retirees [34]. Therefore, older adults were likely to use a DHC to stay healthy before and after retirement. The DHC was expected to provide them with information about social and cultural events and the rights of older people and pensioners. They would also like a coach that could adapt to their needs and motivate them to a healthy lifestyle.

It is worth mentioning that at the beginning of the discussion, it was quite challenging for focus-group participants to imagine how the technology could meet their needs for health. This might depend on the fact that they felt well and had no health condition (in fact, being in good health was one of the inclusion criteria). Moreover, there was a prejudice among the participants related to the technology, which they considered useful just as assistive device for older people with disabilities. In essence, the participants failed to understand the potential of the DHC as a preventive means in the hands of people who are still healthy and fully self-sufficient like them. As consequence, in the participants' opinion, the usage of the DHC might lead to the stigmatization of older users as sick and disabled. This suggests that the first step towards the acceptance of this type of technology is the knowledge of what it can offer and of its potential. This knowledge can lead to the deconstruction of stereotypes and to a better perception of the technology that can be accepted only when older adults see a benefit from its use [59-61]. Obviously older adults with low digital literacy cannot fully take advantage from the DHC and therefore they cannot enjoy all its benefits. For this reason, any program based on the use of a DHC should be introduced by training to develop both digital literacy and health awareness, such that individuals can develop e-health literacy [37,62], and so fully exploit the potential of the DHC. The good health and digital literacy of participants opens the scenario of an increasingly larger segment of technology users over the next few decades being more conscious about their attitudes toward barriers and drivers to the use technology. In fact, the idea to have a DHC was 
lively discussed within the three groups. Someone defended the freedom of being master of one's own time after retirement, i.e., the chance for choosing what to do, when, and where, without the interference of the DHC. Conversely, someone else underlined the need for planning this time in order to make it fruitful (i.e., free but not empty) by means of the DHC.

In light of the above, the DHC challenge seems to stand on the capability of reaching a balance between the user's decision-making capability and the DHC stimulation and motivation. The solution to this dilemma may lie on the synthesis of universal (inclusive) design concept $[63,64]$, and on a customized, flexible, and smart programming based on users' personal interests, designed in an end-users-driven perspective [43].

\subsection{Innovations and Limitations}

To our best knowledge, this is one of the few studies on the use of a DHC aiming at promoting older adults' healthy aging in its meaning of a multidimensional concept going beyond the physical health and embedding even its social and psychological determinants. This study, indeed, has two innovative aspects.

The first lies in having focused attention on a group of older adults, aged between 55 and 70 years, who are often overlooked by research on the development and use of technology. This is due the fact that most of the attention of the scholars in this field has been paid to technology targeting older people with long-term care needs and so with assistive more than with preventive functions. On the contrary, the involvement of people in the 55-70 age range may allow prompt interception of the needs of a group of people who are entering old age and starting a new phase of life marked by retirement.

The second element of innovation lies in considering the DHC system as a technology whose potential is still underexplored, especially when applied to older adults in transition to retirement and for purposes related to healthy aging.

The principal strength of this study was the involvement of people in different stages of life, i.e., older workers and retirees who could give their personal opinion on aging, retirement, and health, thus providing a dynamic perspective as required by a dynamic process such as the transition from work to retirement. This study provides several insights on what people between 55 and 70 years may think about the possibility of being supported by the technology for aging healthy and about which may be the role of a DHC in promoting healthy and independent life of retirees. Nevertheless, this study was not without limitations.

First, the restricted number of participants as well as the specific Italian national context and culture, i.e., representations of work, retirement, technology, national legislation on retirement [27], do not allow the generalization of the outcomes. Moreover, the study did not consider several factors, such as social class, cognitive ability, and education, which might influence the pathway to retirement and the life after retirement [65]. In fact, the participants involved were characterized by a medium-high level of education and by a good digital and health literacy, which could have influenced their responses, oriented the general trend of the choral discussion, and hidden the barriers to technology use that are often common among (older) people with lower education, income, and social inclusion [34]. Third, the whole sample was characterized by an active adoption of technologies and use of the internet that might have created a bias on participants' perspectives, since having experiences with technology during the working life can shape attitudes towards the use of technology later in life [34]. Furthermore, no gender analysis was carried out, due to the limited number of the Italian sample participants. Nevertheless, the gender perspective will be considered for the investigation of future longitudinal cross-national data emerging from the AgeWell project.

\subsection{Suggestions for Future Research and Policy}

From these limitations, some suggestions for future research can be derived. First, more studies exploring the efficacy of DHC systems in supporting health and well-being of older people in transition from work to retirement are recommended, because this topic is still underdeveloped. Second, it is 
suggested that people in different life phases be involved in these studies, as it has been done in this study, which involved older workers, retirees, and their colleagues/excolleagues. In fact, this may allow for gathering multiperspective opinions on the representations of aging, retirement, health, and use of technology, since these concepts change throughout the course of life. Moreover, we suggest adopting a mixed-method approach in future research on this topic. As retirement is a personal experience indeed, the qualitative approach may ensure to capture the different ways to interpret this experience, while the quantitative approach involving large samples may support the generalizability and the transferability of findings. Furthermore, cross-national studies on the current topic are recommended for supporting the comparability of the outcomes read through the lens of the national legislative, cultural, social, and economic context, as well as further investigations. Future studies should also involve participants with different educational levels, economic conditions, and sociocultural origins in order to assess possible correlation between these variables, the representations of health and retirement, and the trust in the efficacy of DHC systems supporting healthy aging.

Finally, the recent coronavirus pandemic has forced many governments to take measures of physical distancing, which has often become social distancing, of people for containing the infection, thus introducing further complications to health and well-being especially among older adults [66]. In similar situations, when it should be not possible to meet in person and to attend gyms and public spaces, the DHC could motivate older adults to continue carry out physical activity, create cultural and entertainment moments, and build new relationship spaces through the creation of virtual communities where activities and results could be shared. DHC could thus mitigate the consequences of physical distancing and help the elderly to continue walking on the path of healthy aging by practicing physical activity at home [67]. In this concern, public policies would be welcome which support digital and health literacy and the adoption of simple, user-friendly, and not expensive digital solution that, like the DHC, may promote healthy lifestyles among all older adults, even those with fewer economic opportunities and a medium-low level of education.

\section{Conclusions}

Digital health coach technology may have an important potential in supporting older adults in their transition from work to retirement and mitigating the possible negative effects on health and well-being of this crucial existential change. The end-users involved in this study identified several functions of the DHC for helping older adults living healthy and active longer: helping users plan and recall leisure, cultural, and social activities; giving input for practicing physical activity; and stimulating cognitive capabilities by stimulating curiosity.

The DHC technology needs to be further developed and tested with older adults in order to design a tool that can meet users' needs and expectations. Once the DHC will be fully acceptable and usable, it will be able to shape the sustainability of care systems by intercepting the health needs of older adults in an early stage, and preventing them from social isolation, sedentary, and psychological discomfort, thus hindering the onset of chronic disease and multimorbidity.

Author Contributions: Conceptualization, S.S. and V.S.; methodology, S.S.; formal analysis, S.S.; data curation, S.S. and V.S.; writing — original draft preparation, S.S., V.S., and F.G.; writing—review and editing, S.S. and V.S.; visualization, F.G.; supervision, J.K. All authors have read and agreed to the published version of the manuscript.

Funding: This research was co-funded by Active and Assisted Living Programme, AAL-call 2018 under the reference no. aal-2018-5-92-CP, and by Ricerca Corrente funding from the Italian Ministry of Health to IRCCS INRCA.

Conflicts of Interest: The authors declare no conflict of interest.

\section{References}

1. Eurostat. Available online: https://ec.europa.eu/eurostat/documents/3217494/10166544/KS-02-19\%E2\%80\% 91681-EN-N.pdf/c701972f-6b4e-b432-57d2-91898ca94893 (accessed on 22 July 2020). 
2. Eurostat. Available online: https://ec.europa.eu/eurostat/statistics-explained/index.php/Healthy_life_years_ statistics (accessed on 7 July 2020).

3. Brennan, P.; Perola, M.; Van Ommen, G.; Riboli, E.; European Cohort Consortium. Chronic disease research in Europe and the need for integrated population cohorts. Eur. J. Epidemiol. 2017, 32, 741-749. [CrossRef] [PubMed]

4. Ec. Europa.eu. Available online: https://ec.europa.eu/info/sites/info/files/file_import/ip037_vol1_en_2.pdf (accessed on 22 July 2020).

5. WHO. What Is Healthy Ageing. Available online: https://www.who.int/ageing/healthy-ageing/en/ (accessed on 19 July 2020).

6. WHO. World Report on Ageing and Health. Available online: https://apps.who.int/iris/bitstream/handle/ 10665/186463/9789240694811_eng.pdf?sequence=1 (accessed on 7 July 2020).

7. Lynch, J.; Smith, G.D. A life course approach to chronic disease epidemiology. Ann. Rev. Public Health 2005, 26, 1-35. [CrossRef]

8. Osler, M. The life course perspective: A challenge for public health research and prevention. Eur. J. Public Health 2006, 16, 230. [CrossRef] [PubMed]

9. Foster, L.; Walker, A. Active and successful aging: A European policy perspective. Gerontologist 2015, 55, 83-90. [CrossRef] [PubMed]

10. UNDP.org. Available online: https://www.undp.org/content/undp/en/home/librarypage/poverty-reduction/ ageing--older-persons-and-the-2030-agenda-for-sustainable-develo.html (accessed on 19 July 2020).

11. WHO. Constitution. Available online: https://www.who.int/about/who-we-are/constitution\#: \{\{\}: text $=$ Health $\% 20$ is $\% 20$ a $\% 20$ state $\% 20$ of,absence $\% 20$ of $\% 20$ disease $\% 20$ or $\% 20$ infirmity.\&text=The $\%$ 20achievement $\% 20$ of $\% 20$ any $\% 20$ State, is $\% 20$ of $\% 20$ value $\% 20$ to $\% 20$ all (accessed on 7 July 2020).

12. WHO. World Report on Ageing and Health. Available online: www.who.int/ageing/publications/worldreport-2015/en/ (accessed on 20 December 2019).

13. McCarthy, J.; Heraty, N.; Cross, C.; Cleveland, J.N. Who is considered an 'older worker'? Extending our conceptualisation of 'older' from an organisational decision maker perspective. Hum. Resour. Manag. J. 2014, 24, 374-393. [CrossRef]

14. Fernández-Niño, J.A.; Bonilla-Tinoco, L.J.; Manrique-Espinoza, B.S.; Romero-Martínez, M.; Sosa-Ortiz, A.L. Work status, retirement, and depression in older adults: An analysis of six countries based on the Study on Global Ageing and Adult Health (SAGE). SSM Popul. Health 2018, 6, 1-8. [CrossRef]

15. Lucas, A.; Daniel, F.; Guadalupe, S.; Massano-Cardoso, I.; Vicente, H. Time spent in retirement, health and well-being. Eur. Psychiatry 2017, 41, 339-340. [CrossRef]

16. Kolodziej, I.W.K.; García-Gómez, P. Saved by retirement: Beyond the mean effect on mental health. Soc. Sci. Med. 2019, 225, 85-97. [CrossRef]

17. Eibich, P. Understanding the Effect of Retirement on Health: Mechanisms and Heterogeneity. J. Health Econ. 2015, 43, 1-12. [CrossRef]

18. Shai, O. Is retirement good for men's health? Evidence using a change in the retirement age in Israel. J. Health Econ. 2018, 57, 15-30. [CrossRef]

19. Lindwall, M.; Berg, A.I.; Bjälkebring, P.; Buratti, S.; Hansson, I.; Hassing, L.; Henning, G.; Kivi, M.; König, S.; Thorvaldsson, V.; et al. Psychological Health in the Retirement Transition: Rationale and First Findings in the HEalth, Ageing and Retirement Transitions in Sweden (HEARTS) Study. Front. Psychol. 2017, 8, 16-34. [CrossRef]

20. Wetzel, M.; Huxhold, O.; Tesch-Römer, C. Transition into Retirement Affects Life Satisfaction: Short- and Long-Term Development Depends on Last Labor Market Status and Education. Soc. Indic. Res. 2016, 125, 991-1009. [CrossRef]

21. Atchley, R.C. The Sociology of Retirement, 1st ed.; John Wiley \& Sons Inc.: New York, NY, USA, 1976.

22. Wang, M.; Henkens, K.; Van Solinge, H. Retirement adjustment: A review of theoretical and empirical advancements. Am. Psychol. 2011, 66, 204-213. [CrossRef] [PubMed]

23. Rohwedder, S.; Willis, R.J. Mental Retirement. J. Econ. Perspect. 2010, 24, 119-138. [CrossRef] [PubMed]

24. Santini, S.; Socci, M.; Principi, A. Health and wellbeing during the transition to retirement: The more the fears the less the actions? In Proceedings of the Third ISA Conference, Vienna, Austria, 10-14 July 2016; Available online: https://isaconf.confex.com/isaconf/forum2016/webprogram/Paper76971.html (accessed on 8 September 2020). 
25. Fasang, A.E. Retirement Patterns and Income Inequality. Soc. Forces 2012, 90, 685-711. [CrossRef]

26. Szinovacz, E.M.; Martin Palmer, L.A.; Davey, A. Recession and Expected Retirement Age: Another Look at the Evidence. Gerontologist 2013, 54, 245-257. [CrossRef] [PubMed]

27. Principi, A.; Galenkamp, H.; Papa, R.; Socci, M.; Suanet, B.; Schmidt, A.; Schulmann, K.; Golinowska, S.; Sowa, A.; Moreira, A.; et al. Do predictors of volunteering in older age differ by health status? Eur. J. Ageing 2016, 13, 91-102. [CrossRef] [PubMed]

28. Yeung, D.Y.; Zhou, X. Planning for Retirement: Longitudinal Effect on Retirement Resources and Post-retirement Well-being. Front. Psychol. 2017, 8, 1300. [CrossRef]

29. Dannii, Y.Y. Is pre-retirement planning always good? An exploratory study of retirement adjustment among Hong Kong Chinese retirees. Aging Ment. Health 2013, 17, 386-393.

30. Prinicipi, A.; Smeathon, D.; Kahill, K.; Santini, S.; Barnes, H.; Socci, M. What happens to retirement plans, and does it affect retirement satisfaction? Int. J. Aging Hum. Dev. 2018, 90, 1-24. [CrossRef]

31. Hershenson, D.B. Reconceptualizing retirement: A statuses-based approach. J. Aging Stud. 2016, 38, 1-5. [CrossRef] [PubMed]

32. Cook, R.F.; Hersch, R.K.; Schlossberg, D.; Leaf, S.L. A Web-Based Health Promotion Program for Older Workers: Randomized Controlled Trial. J. Med. Internet Res. 2015, 17, 82. [CrossRef]

33. Irvine, A.B.; Gelatt, V.A.; Seeley, J.R.; Macfarlane, P.; Gau, J.M. Web-based intervention to promote physical activity by sedentary older adults: Randomized controlled trial. J. Med. Internet Res. 2013, 15, 19. [CrossRef] [PubMed]

34. Czaja, S.J.; Boot, W.R.; Charness, N.; Rogers, W.A. Designing for Older Adults: Principles and Creative Human Factors Approaches, 2nd ed.; CRC Press: Boca Raton, FL, USA, 2019.

35. McCreadie, C.; Tinker, A. The acceptability of assistive technology to older people. Ageing Soc. 2005, 25, 91-110. [CrossRef]

36. Melenhorst, A.S.; Rogers, W.A.; Caylor, E.C. The use of communication technologies by older adults: Exploring the benefits from the user's perspective. In Proceedings of the Human Factors and Ergonomics Society Annual Meeting, Minneapolis, MN, USA, 8-12 October 2001; SAGE Publications: Thousand Oaks, CA, USA; Volume 45, pp. 221-225.

37. Lee, C.; Coughlin, J.F. Perspective: Older adults' adoption of technology: An integrated approach to identifying determinants and barriers. J. Prod. Innov. Manag. 2015, 32, 747-759. [CrossRef]

38. Davis, F.D. Perceived Usefulness, Perceived Ease of Use, and User Acceptance of Information Technology. MIS Q. 1989, 13, 319-339. [CrossRef]

39. Davis, F.D.; Bagozzi, R.P.; Warshaw, P.R. User Acceptance of Computer Technology: A Comparison of Two Theoretical Models. Manag. Sci. 1989, 35, 982-1002. [CrossRef]

40. Shinohara, K.; Wobbrock, J.O. In the shadow of misperception: Assistive technology use and social interactions. In Proceedings of the SIGCHI Conference on Human Factors in Computing Systems, Vancouver, BC, Canada, 7-12 May 2011.

41. Soderstrom, S.; Ytterhus, B. The use and non-use of assistive technologies from the world of information and communication technology by visually impaired young people: A walk on the tightrope of peer inclusion. Disabil. Soc. 2010, 25, 303-315. [CrossRef]

42. Greenhalgh, T.; Wherton, J.; Papoutsi, C.; Lynch, J.; Hughes, G.; Christine A'Court, C.; Susan Hinder, S.; Fahy, N.; Procter, R.; Shaw, S.; et al. Beyond adoption: A new framework for theorizing and evaluating non adoption, abandonment, and challenges to the scale-up, spread, and sustainability of health and care technologies. J. Med. Internet Res. 2017, 19, 367. [CrossRef]

43. ISO. Ergonomics of Human-System Interaction. Available online: http://www.iso.org/iso/catalogue_detail. htm?csnumber=52075 (accessed on 16 July 2020).

44. Etikan, I.; Abubakar Musa, S.; Alkassim, R.S. Comparison of Convenience Sampling and Purposive Sampling. Am. J. Theor. Appl. Stat. 2016, 5, 1-4. [CrossRef]

45. Bernard, H.R. Research Methods in Anthropology: Qualitative and Quantitative Approaches, 3rd ed.; Alta Mira Press: Walnut Creek, CA, USA, 2002.

46. Shultz, K.S.; Wang, M. Psychological perspectives on the changing nature of retirement. Am. Psychol. 2011, 66, 170-179. [CrossRef] [PubMed]

47. Wang, M.; Shultz, K.S. Employee Retirement: A Review and Recommendations for Future Investigation. J. Manag. 2010, 36, 172-206. [CrossRef] 
48. Maramba, I.; Chatterjee, A.; Newman, C. Methods of usability testing in the development of eHealth applications: A scoping review. Int. J. Med. Inf. 2019, 126, 95-104. [CrossRef] [PubMed]

49. Noble, H.; Smith, J. Issues of validity and reliability in qualitative research. Evid. Based Nurs. 2015, 18, 34-35. [CrossRef]

50. Lincoln, Y.S.; Guba, E.G. Naturalistic Inquiry; Sage: Beverly Hills, CA, USA, 1985.

51. Morse, J.; Barrett, M.; Mayan, M.; Olson, K.; Spiers, J. Verification strategies for establishing reliability validity in qualitative research. Int, J. Qual. Res. 2002, 1, 1-19. [CrossRef]

52. Slevin, E. Enhancing the truthfulness, consistency, and transferability of a qualitative study: Using a manifold of two approaches. Nurs. Res. 2002, 7, 79-197. [CrossRef]

53. Fraser, S.; Greenhalgh, T. Coping with complexity: Educating for capability. BMJ 2001, 323, 799-803. [CrossRef]

54. Sandelowski, M. Rigor or rigor mortis: The problem of rigor in qualitative research revisited. Adv. Nurs. Sci. 1993, 16, 1-8. [CrossRef]

55. DeSantis, L.; Ugarriza, D.N. The Concept of Theme as Used in Qualitative Nursing Research. West. J. Nur. Res. 2000, 22, 351-372. [CrossRef]

56. Braun, V.; Clarke, V. Using thematic analysis in psychology. Qual. Res. Psychol. 2006, 3, 77-101. [CrossRef]

57. Vaismoradi, M.; Bondas. T.; Turunen, H. Content Analysis and Thematic Analysis: Implications for Conducting a Qualitative Descriptive Study. J. Nurs. Health Sci. 2013, 15, 398-405. [CrossRef] [PubMed]

58. Rabiee, F. Focus-Group Interview and Data Analysis. Proc. Nutr. Soc. 2004, 63, 655-660. [CrossRef] [PubMed]

59. Charles, S.; Carstensen, L.L. Social and Emotional Aging. Annu Rev. Psychol. 2010, 61, 383-409. [CrossRef] [PubMed]

60. Guner, H.; Acarturk, C. The use and acceptance of ICT by senior citizens: A comparison of technology acceptance model (TAM) for elderly and young adults. Univ. Access Inf. Soc. 2020, 19, 311-330. [CrossRef]

61. Chen, K.; Chan, A.H. A review of technology acceptance by older adults. Gerontechnology 2011, 10, 1-12. [CrossRef]

62. Levin-Zamir, D.; Bertschi, I. Media health literacy, eHealth literacy, and the role of the social environment in context. Int. J. Environ. Res. Public Health 2018, 15, 1643. [CrossRef]

63. Kim, H.; Xie, B. Health literacy in the eHealth era: A systematic review of the literature. Patient Educ. Couns. 2017, 100, 1073-1082. [CrossRef]

64. Story, M.F. Principles of universal design. In Universal Design Handbook; McGraw-Hill Inc.: New York, NY, USA, 2001.

65. Story, M.F.; Mueller, J.L.; Mace, R.L. The Universal Design File: Designing for People of All Ages and Abilities; Center for Universal Design, NC State University: Raleigh, NC, USA, 1998; Available online: http: //www.design.ncsu.edu (accessed on 8 September 2020).

66. Tyrrell, C.J.; Williams, K.N. The paradox of social distancing: Implications for older adults in the context of COVID-19. Psychol. Trauma Theory Res. Pract. Policy 2020, 12, 214-216. [CrossRef]

67. Goethals, L.; Barth, N.; Guyot, J.; Hupin, D.; Celarier, T.; Bongue, B. Impact of Home Quarantine on Physical Activity Among Older Adults Living at Home During the COVID-19 Pandemic: Qualitative Interview Study. JMIR Aging 2020, 3.

(C) 2020 by the authors. Licensee MDPI, Basel, Switzerland. This article is an open access article distributed under the terms and conditions of the Creative Commons Attribution (CC BY) license (http://creativecommons.org/licenses/by/4.0/). 